\title{
Research on the Construction of Teaching Quality Evaluation System of Modern Distance Education
}

\author{
Xiaodun Deng \\ Xi'an International University, 710077, Xi'an Shaanxi, China
}

Keywords: Modern Distance Education; teaching quality evaluation system; construction strategy

\begin{abstract}
The modern distance education is an important form of innovation and development of our country's education system, and it has very important influence on the sustainable development of China's education industry. On this basis, based on the overview of modern distance education, this paper analyzed the construction principle of modern distance education teaching quality evaluation system. This paper focuses on strategies for the construction of modern distance education teaching quality evaluation system, and establishes the quality evaluation system to match with the modern distance education system, promoting the new developments of China's socialist education.
\end{abstract}

\section{Introduction}

The development history of modern distance education in China has been more than 20 years, along with the popularization of education process continues to accelerate, the development of modern distance education is of vital value in the socialist education system in China, and made great contribution to the construction and development of education in our country. At present, in order to better carry out and implement the strategy of education,we need the help of science and education, modern distance education teaching quality evaluation system, provide an important index for the perfection and development of modern distance education and sustainable development, in order to better promote the modern distance education's rapid development in China. In this regard, the content of modern distance education teaching quality evaluation system for main research on. The construction principle and construction strategies are briefly discussed in order to provide a reference for the related researchers.

\section{An overview of Modern Distance Education}

Modern distance education is based on the technology of Internet technology and information science, with the help of efficient teaching knowledge of Internet Education Platform of education, modern distance education largely broke the time and space constraints in the traditional education mode, and to accelerate the process of development of public education and realize the construction of "learning type" significance to achieve social goals is crucial. Take the time as the division basis, the modern distance education mode can be divided into two parts, respectively is the real-time and non-real time model of modern distance education and modern distance education mode, real-time teaching and explain the former focuses on knowledge points, teachers to explain and spread through the Internet way, the knowledge transfer to every audience of students, the latter is that teachers prepare the teaching contents in video, audio in the form of recording in advance for students learning whenever and wherever possible. And it can be learned for the students repeatedly [1]. Teaching at the present stage, with the deepening of the reform of the education system of our country, the development of modern distance education, modern distance education pilot universities set up more than 70, and gradually become an important way for students to continue the daily learning. Among them, the modern distance education includes the following characteristics:

First, rich in resources. Modern distance education based on Internet to provide the new development service platform for students, in order to meet the needs of students' physical and 
mental development of the reality, the online education can effectively integrate various high-quality educational resources for different levels, to provide professional, teaching content the diverse needs of students.It plays a positive role in promoting and optimizing the teaching structure. At the same time, rich teaching resources can be run through the modern distance education system and it has laid the foundation for the improvement of students' comprehensive ability and learning effect maximization.

Second, science and technology. Modern distance education is beneficial to the integration of science and technology and hardware facilities, it is the inevitable trend of the development of the information era for that is more in-depth practice of lifelong learning concept. In the process of education, students need to achieve professional knowledge through modern distance education learning platform, and in which high quality modern distance educational facilities is an important guarantee to realize the maximum teaching effect, the related hardware, facilities, software infrastructure requirements are relatively high, the content of science and technology in modern distance education is in a large proportion.

Third, improve the management of modern distance education is a kind of innovation. The development of the traditional teaching mode, the Internet technology and the concept of classroom teaching by combining the transformation of classroom teaching mode in the process of upgrading, promote the development of education modernization. At the same time, also increased the difficulty of management education activities, encourage educators to pay more attention to the management efficiency the promotion, and further improve the management mechanism of modern distance education. In addition, modern distance education should also guide the program for students to preview and review daily to make important education, establish and improve the relevant supporting services.

Fourth students. The modern distance education is an important part of quality education system, but also an important part of higher education in China, in the process of education, should uphold the educational idea of students, based on the need of physical and mental development of students, respect students' individual differences, for students in the learning process the questions or concerns explain patiently, so as to make the teaching tactics.

\section{The construction principle of modern distance education teaching quality evaluation system}

The construction should follow the principle of nature of modern distance education teaching quality evaluation system of modern distance education and traditional classroom teaching mode with distinctive features compared to compatibility and personalized, it can develop personalized teaching scheme and the corresponding according to the different needs of students, and presents the online teaching content of novelty and richness coexist for students through science reasonable teaching method, so as to maximize the mobilization of students' initiative and enthusiasm in learning ${ }^{[2]}$. Therefore, the actual needs in the construction process of quality evaluation system based on the students, respect for individual differences of students, and implement the teaching strategy of the teaching plan should take the student as the main starting point, and taking into account it is to highlight the dominant position of students.

The construction should follow the principle of quality of modern distance education teaching quality evaluation system of teaching quality evaluation system is an important guarantee for the development of Modern Distance Education in Colleges and universities, educators and related departments according to the quality of teaching evaluation system reflects the content, timely and accurate adjustment of teaching objectives and teaching content of their own, in order to achieve the main purpose to improve the overall teaching level. In this regard, the construction of modern distance education quality evaluation system should be to improve the overall quality of teaching as the basic goal, formulate and conform to the quality standards and evaluation mechanism, so as to make scientific and effective professional guidance to it.

The construction should follow the principle of autonomy of modern distance education teaching quality evaluation system of modern distance education is the integration of the development of modern network technology and teaching mode, breaking the traditional teaching mode in time and 
space constraints, under the model of modern distance education, students can according to their learning needs and growth needs corresponding of course, this requires the students to have the ability of studying independently. Thus, the teaching quality evaluation system in Modern Distance Education Based on the students' ability of autonomous learning, autonomous learning awareness evaluation systematic and comprehensive, and this is an important principle of construction.

The construction of modern distance education teaching quality evaluation system should follow the development principle.The principle of development refers to the teaching of modern distance education quality evaluation system, index, methods and related content to cater to the development trend of the times, in line with the requirements of physical and mental development of students at this stage, there is conducive to enhance students' comprehensive ability, make an important contribution in order to promote the stable development of modern distance education, and the development of principles and implement in modern distance education teaching quality evaluation system, to achieve maximum effect evaluation.

\section{The construction strategy of modern distance education teaching quality evaluation system}

To strengthen the teaching idea and teaching quality of modern distance education, laid an important ideological basis for the construction of modern distance education teaching quality evaluation system, and carry out scientific and rational thought for their guidance, so as to improve the effectiveness of teaching quality evaluation system of teaching. The teaching quality of modern distance education to establish the teaching activities as the starting point according to the practical situation, the current physical and mental development of students, respect students' subject status in the teaching process, the goal of precise positioning, training of personnel in this regard, from mission, curriculum construction, comprehensive evaluation of cognitive ability, according to the actual situation of the development of the market, pay attention to the cultivation of talents, talents and skills the theory of talents, in order to meet the objective needs of the socialist modernization of our country.

To strengthen the teaching quality of modern distance education evaluation environment construction, from two aspects of hardware and software environment evaluation of the objective evaluation of modern distance education and the overall level of quality, so that will be more accurate and objective description of modern distance education system in the overall development, to provide quality talents of all-round development for our country socialism the modernization construction, promote the new development of Modern Distance Education in our country. To adhere to the principle of quantitative analysis and qualitative analysis, to analyze the quality of modern distance teaching evaluation environment on the one hand, the scientific evaluation of Modern Distance Education in the hardware environment, such as teaching equipment, multimedia equipment, laboratory equipment, lay the foundation for the students' practical ability improved; on the other hand, to strengthen the evaluation of software specifications, such as teachers, funding policy, education investment Entry should be not less than the minimum index.

Pay attention to the quality of modern distance education teaching presentation. As everyone knows, the teaching effect can accurately reflect the teaching efficiency and teaching level, in the development of modern education system, teaching effect will gradually become an important index for the evaluation of classroom teaching quality. Teachers and students as the main body of Modern Distance Education, construction of the teaching quality evaluation system it should start with the two aspects one by one evaluation of the two, combined with social factors, and the smooth progress of scientific construction of quality assurance and evaluation system so as to effectively. On the one hand, the two aspects of teaching satisfaction evaluation by students and social comprehensive peer assessment, usually dominated by online survey, the satisfaction rate should not be less than 60\%; on the other hand, the teaching evaluation should cover the employment situation of students and research results of these two aspects, the employment rate of students should be not less than $80 \%$ per In each year, the overall research results of the teachers should be no less than 3 [3].

We should pay close attention to the overall quality of the quality of modern distance education, 
adhere to the principle of building development, based on the long-term development of modern distance education, the indexes of the modern distance education and career development, comprehensive analysis and evaluation system of factors, at the same time, in the process of evaluation, to quantify the corresponding evaluation index according to the actual situation is considered to be the evaluation contents, at the same time pay attention to improving the overall quality of teaching, pay attention to the modern distance education contents and conditions to enhance development. In addition, under the guidance of the concept of quality of the development of modern distance education institutions, resources, facilities, evaluation of investment overall situation, aiming at its weakness the targeted recommendations for improvement, so as to improve the overall quality of education.

\section{Summary}

The rapid development of social economy,science and technology, provides an important opportunity and a good social environment for the sustainable development of Modern Distance Education in our country, especially under the current background of quality-oriented education, our government and universities have paid great attention to personnel training, to expand the scope of training gradually the creation of the modern distance education system, deepen the breadth and depth of talent training, on this basis, to develop the teaching quality evaluation system and the corresponding concept, from the building, construction environment, rendering quality, focus on four aspects, make an important basis for the development of modern distance education.

\section{Acknowledgement}

Shaanxi Province Higher Education Institute 2015-2016 annual high level private university construction research project, 15GJ044, University distance education service quality evaluation system construction research.

2016 annual Xi'an social science planning fund project, (foreign affairs special), 16IN13 University Online Education Service Quality Evaluation System Construction Research

\section{References}

[1] Zhong Zhixian, Zhang Xiaomei, Shen Jianhua. Research on the distance education teaching quality evaluation system of the "one village one college student project" [J]. China distance education, 2016, 01:32-40 80

[2] Li Juan, Portland. Kihei distance education quality evaluation system of [J]. Contemporary cultural identity of continuing education based on 2016, 04:62-67.

[3] Zhang Binghua. Construction of distance education teaching quality evaluation and guarantee system thinking [J]. Journal of Jiangsu Radio and TV University, 2003, 06:13-15. 